\title{
Atividades externas de Melipona marginata obscurior Moure (Hymenoptera, Apidae), em distintas épocas do ano, em São Francisco de Paula, Rio Grande do Sul, Brasil
}

\author{
Francine von B. Borges \& Betina Blochtein
}

Faculdade de Biociências, Pontifícia Universidade Católica do Rio Grande do Sul. Avenida Ipiranga 6681,90619-900 Porto

Alegre, Rio Grande do Sul, Brasil. E-mail: fvborges@hotmail.com

\begin{abstract}
External activities of Melipona marginata obscurior Moure (Hymenoptera, Apidae), in distinct times of the year, at São Francisco de Paula, Rio Grande do Sul, Brazil. It is proposed a seasonal analysis of the external activities of Melipona marginata obscurior Moure, 1971, in different times of the year. The flight activities of the bees of colonies were studied in the Centro de Pesquisas e Conservação da Natureza Pró-Mata, at São Francisco de Paula, Rio Grande do Sul. In the spring-summer period, the diary amplitude of the flight activity was about 9 and 13 hours to the colonies $A$ and $B$, respectively, with more flight intensity between 9 and 11 o'clock. The flight minimum temperature was about $14,3^{\circ} \mathrm{C}$ and from this one they became more intense. The most flight intensity has occurred about $81-90 \%$ of relative humidity and $300 \mathrm{~W} / \mathrm{m}^{2}$ of solar radiation. For the A colony, the bees flight activity was significantly influenced only by the temperature, while for the B colony it was influenced only by the solar radiation. In autumn-winter period, the diary amplitude of the flight activities was about 10 hours, and between 10 and 15 o'clock these activities were more intense. The flight minimum temperature was about $13,7^{\circ} \mathrm{C}$, and from this temperature the activities became more intense. As in the spring-summer period, the most flight intensity in this period had occurred in about $300 \mathrm{~W} / \mathrm{m}^{2}$ of solar radiation. The temperature and the solar radiation had exertised a significant influence in the external activities of the bees on both colonies in the autumn-winter period. The collect pollen activities by the bees, in the spring-summer period, occurred in the first hours of the morning, while in the autumn-winter period the foraging was delayed.
\end{abstract}

KEY WORDS. Manduri, meteorological factors, pollen, stingless bees.

\begin{abstract}
RESUMO. Atividades externas de Melipona marginata obscurior Moure (Hymenoptera, Apidae), em distintas épocas do ano, em São Francisco de Paula, Rio Grande do Sul, Brasil. Propõe-se a análise das atividades de vôo de Melipona marginata obscurior Moure, 1971, em diferentes épocas do ano. Atividades de vôo de abelhas de duas colônias foram estudadas no Centro de Pesquisas e Conservação da Natureza Pró-Mata, em São Francisco de Paula, RS. Na primavera-verão, a amplitude diária de atividade de vôo foi de nove e 13 horas para colônias $A$ e $B$, respectivamente, com maior intensidade de vôo entre nove e 11 horas. A temperatura mínima para vôo foi de $14,3^{\circ} \mathrm{C}$ e a partir desta tornaram-se mais intensas. A maior intensidade de vôo ocorreu na faixa de $81-90 \%$ de umidade relativa e radiação solar a partir de $300 \mathrm{~W} / \mathrm{m}^{2}$. Para a colônia $\mathrm{A}$, apenas a temperatura influenciou significativamente as atividades de vôo das abelhas, enquanto que para a colônia B foi somente a radiação solar. No outonoinverno, a amplitude diária de atividades de vôo foi de 10 horas, e entre 10 e 15 horas estas atividades foram mais intensas. A temperatura mínima para vôo foi de $13,7^{\circ} \mathrm{C}$, e a partir desta temperatura as atividades tornaram-se mais intensas. Assim como na primavera-verão, a maior intensidade de vôo neste período ocorreu a partir de $300 \mathrm{~W} /$ $\mathrm{m}^{2}$ de radiação solar. A temperatura e a radiação solar exerceram influência significativa nas atividades externas das abelhas das duas colônias no outono-inverno. As atividades de coleta de pólen pelas abelhas, na primavera-verão, ocorreram desde as primeiras horas da manhã, enquanto no outono-inverno o forrageamento foi tardio.
\end{abstract}

PALAVRAS CHAVE. Coleta de pólen, manduri, fatores meteorológicos.

Operárias de abelhas sem ferrão, durante suas atividades externas, coletam pólen (fonte protéica) e néctar (carboidratos) além de outros materiais para construção dos ninhos (ABSY \& KERR 1977, Guibu et al. 1988, RAMALHo et al. 1989, 1991, Michener 2000). Estas atividades podem ser influenciadas pela oferta de recursos florais, pelas condições internas das colônias (reserva alimentar, produtividade das rainhas) e por fatores abióticos, tais como temperatura, umidade relativa, intensidade luminosa, precipitação e velocidade do vento (Iwama 1977, Szabo 1980, KLEINERT-GIOvanNINI 1982, Imperatriz-Fonseca et al. 1985, Kleinert-GiovanNini \& IMPERAtriz-Fonseca 1986, Heard \& Hendrikz 1993, Freitas \& Wittmann 1997, Hilário et al. 2000, 2001, Pick \& Blochtein 2002a, b).

Revista Brasileira de Zoologia 22 (3): 680-686, setembro 2005 
Ecologicamente, as atividades de vôo das abelhas fornecem dados fundamentais para o conhecimento da biologia das espécies e sua aplicação na conservação das espécies e planejamento efetivo da polinização de plantas agrícolas (IwAMA 1977).

No Rio Grande do Sul, os trabalhos sobre Meliponinae (Silveira et al. 2002) registram a ocorrência de espécies (WITTMAnN \& Hoffmann 1990. Wilms et al. 1997. Alves-Dos-Santos 1999), a arquitetura de ninhos (WITTMANN 1989), o comportamento reprodutivo (Wittmann et al. 1991, Freitas \& Wittmann 1997) e atividade de vôo durante a diapausa e postura da rainha (PICK $\&$ Blochtern 2002b). No Rio Grande do Sul apenas Plebeia saiqui (Holmberg, 1903) foi estudada quanto às atividades externas em distintas épocas do ano (Pick \& Blochtein 2002a, b).

Melipona marginata obscurior Moure, 1971, assim como a maioria das espécies de Meliponina, é generalista quanto à obtenção de néctar e pólen (KLEINERT-GiovanNINI \& IMPERATRIz-FonseCA 1987) e, até o momento, no Rio Grande do Sul foi relacionada a 59 espécies de plantas (MARQues et al. 2004). Conhecida popularmente como manduri, nidifica em ocos de árvores de médio e grande porte, em alturas superiores a $4 \mathrm{~m}$ (KerR et al. 1996) e em paredões de taipa (Pirani \& Cortopassi-Laurino 1994). A entrada do ninho é típica e destaca-se no centro de estrias convergentes de barro, por onde passa apenas uma abelha (Nogueira-Neto 1970).

Melipona m. obscurior apresenta ampla distribuição, com registro para o estado da Bahia e regiões Sudeste e Sul do Brasil (Silveira et al. 2002). Sua ocorrência no Rio Grande do Sul foi registrada para as localidades de Canela, Cambará do Sul, Caxias do Sul, Osório, Planalto, São Francisco de Paula e Tenente Portela (WitTMann \& HofFmann 1990, Marques et al. 2004).

Apesar do reconhecimento da efetividade das abelhas como agentes polinizadores, o número de colônias de abelhas nativas nas matas brasileiras tem diminuindo acentuadamente em consequência das alterações de seus ambientes, como desmatamentos, queimadas, uso de agrotóxico e ação predatória de meleiros (Aidar 1996, Kerr et al. 1996, Aidar \& CAmpos 1998, Marques et al. 2002, Silveira et al. 2002).

Melipona $m$. obscurior foi incluída, como espécie vulnerável, na Lista Vermelha das Espécies Ameaçadas do Rio Grande do Sul (MARQues et al. 2002). Além dos aspectos da conservação, o conhecimento da ecologia das espécies é essencial para seu manejo na polinização e produção de mel (KeRR et al. 1996, MARQUES et al. 2004). No entanto, no Rio Grande do Sul, ainda não foram realizados estudos a respeito da biologia de $M$. $m$. obscurior.

O presente trabalho tem como objetivo ampliar o conhecimento sobre a biologia de M. m. obscurior, em ambiente de distribuição natural, com a análise das atividades externas das abelhas durante os períodos de primavera-verão e outono-inverno.

\section{MATERIAL E MÉTODOS}

\section{Área de estudo}

O estudo foi desenvolvido no Centro de Pesquisas e Conservação da Natureza Pró-Mata/PUCRS (Pró-Mata), no município de São Francisco de Paula, Rio Grande do Sul $\left(29^{\circ} 27^{\prime}-29^{\circ} 35^{\prime}\right.$ S e $\left.50^{\circ} 08^{\prime}-50^{\circ} 15^{\prime} \mathrm{W}\right)$ (BerToletTi \& Teixeira 1995).

A vegetação predominante na área é constituída pelas Florestas Ombrófila Mista (Mata com Araucária), Ombrófila Densa (Mata Atlântica) e Campos. A maior parte da área do Pró-Mata está situada entre 600 e 900m de altitude onde a declividade é moderada. O clima é superúmido a úmido, com regime pluviométrico oscilando entre 1750 e $2500 \mathrm{~mm}$ anuais (BERTOLETTI \& TeIXeIra 1995).

\section{Procedência e manutenção das colônias}

Duas colônias de $M$. $m$. obscurior (A, B) foram obtidas na Serra Geral, em sua área natural de distribuição, e transferidas para caixas de madeira de $3 \mathrm{~cm}$ de espessura e com medidas externas de $37 \times 28 \times 18 \mathrm{~cm}$, tampadas por placas de vidro transparente, cobertas com isopor e tampa de madeira. As colônias foram dispostas sobre uma bancada, no laboratório na sede do Pró-Mata, e as caixas foram interligadas, através da parede ao exterior, com mangueira plástica (6 mm de diâmetro). Alimentação artificial (1 água: 1 açúcar) foi oferecida às colônias, quando havia pouca reserva de alimento nos potes.

\section{Atividades de vôo e coleta de pólen}

As atividades de vôo das abelhas das colônias A e B foram registradas nos períodos de primavera-verão $(26 / 09,27 / 09,2$ / $11,4 / 12 / 2002$ e $08 / 01,09 / 01 / 2003)$; e outono-inverno $(28 / 03$, 29/03, 29/05, 30/05, 25/06 e 26/06/2003). Conforme descrito por Oliveira (1973), foram realizadas observações junto às entradas dos ninhos, a cada dia, do início até o término das atividades de vôo, com auxílio de um contador manual durante 10 minutos a cada hora, totalizando 83 e 72 observações respectivamente na primavera-verão e no outono-inverno. Registrou-se o número de operárias que retornavam às colônias, anotando-se as que transportavam pólen nas corbículas e outros materiais, sem distinção de água, néctar, barro ou própolis.

\section{Parâmetros meteorológicos $\mathrm{x}$ atividades externas}

Os registros de temperatura, velocidade do vento, umidade relativa e radiação solar, foram obtidos em intervalos de uma hora, por meio da estação meteorológica DAVIS, instalada a aproximadamente três metros das colônias.

A influência dos parâmetros meteorológicos sobre as atividades externas das colônias, foi avaliada durante os períodos primavera-verão (2002-2003) e outono-inverno (2003). Devido a falhas na estação meteorológica os dados de umidade relativa do período de outono-inverno e de radiação solar, nos dias 25 e 26/06/2003, não foram considerados. Para verificar a significância de cada fator meteorológico isoladamente foi aplicada regressão simples usando-se do programa MS Excel ${ }^{\circledR}$.

\section{RESULTADOS E DISCUSSÃO}

Analizou-se comparativamente, nos períodos de primavera-verão e outono-inverno, a influência dos fatores meteorológicos sobre o ritmo diário das atividades externas de Melipona marginata obscurior. 
Ao longo do dia, as atividades de vôo das operárias que retornaram às colônias, no período de primavera-verão, aumentaram gradualmente das 6:00 às 10:00 h na colônia $\mathrm{B}$ e das 7:00 às 11:00 h na colônia $\mathrm{A}$ (Fig. 1). Após estes horários as atividades diminuíram, cessando às 15:00 h na colônia $\mathrm{A}$ e às 18:00 h na colônia B. Assim, a amplitude máxima diária de atividades de vôo registrada foi de 13 e 9 horas, respectivamente nas colônias B e A e a maior intensidade de vôo, em ambas colônias, ocorreu entre 9:00 e 11:00 h.

No período de outono-inverno, a amplitude de vôo das duas colônias, foi de $10 \mathrm{~h}$ (Fig. 2), iniciando às 8:00 h e cessando às 17:00 h. Neste período a maior intensidade das atividades de vôo ocorreu entre 10:00 e 15:00 h. Na colônia A, a partir das 10:00 h houve decréscimo das atividades de vôo, enquanto na colônia $B$, não se percebe tendência de curva normal.

As atividades de vôo de M. marginata obscurior, observadas no Rio Grande do Sul diferem daquelas registradas, para $M$. marginata marginata Lepeletier, 1836 e M. marginata obscurior em São Paulo (Kleinert-Giovannini \& ImPeratriz-Fonseca 1986). Ao longo do ano, o período de maior atividade para as duas subespécies em São Paulo ocorreu entre 11:00 e 13:00 h. No Rio Grande do Sul, a maior intensidade de vôo de M. marginata obscurior concentrou-se no período matutino, durante a primavera-verão (Fig. 1), enquanto no outono-inverno, estendeuse desde o final da manhã até à tarde (Fig. 2). Além da influência direta das variações meteorológicas, a alteração do comportamento externo das operárias pode ser atribuída à variação diária e/ou sazonal do fluxo de recursos alimentares, em concordância com a interpretação de HiLário et al. (2000).

Os limites inferiores de temperatura registrados para atividades de vôo de $M$. $m$. obscurior, foram de $14,3^{\circ} \mathrm{C}$ na primavera-verão e de $13,7^{\circ} \mathrm{C}$ no outono-inverno (Tab. I), e a partir destes valores tendem a tornaram-se mais intensas nos dois períodos (Figs 3 e 4). Em estudos com a mesma subespécie, em São Paulo (janeiro-julho/1982), a temperatura registrada para o início dos vôos foi de $17-18^{\circ} \mathrm{C}$, com maior intensidade das atividades entre $21-28^{\circ} \mathrm{C}$ (KLeINERT-GiovanNini \& IMPERATriz-FonseCA 1986).

Em M. quadrifasciata quadrifasciata Lepeletier, 1836 foi registrado início das atividades em $13^{\circ} \mathrm{C}$ e maior intensidade de vôo entre $14-16^{\circ} \mathrm{C}$ (IMPERATRIZ-Fonseca et al. 1985) e para $M$. bicolor bicolor Lepeletier, 1836 o início das atividades de vôo ocorreu entre $11-16^{\circ} \mathrm{C}$, apresentando maior intensidade de vôo entre $16-26^{\circ} \mathrm{C}$ (HILÁrio et al. 2000). Já, M. m. marginata apresentou início das atividades de vôo a partir de $14^{\circ} \mathrm{C}$, com maior intensidade de vôo entre $19-30^{\circ} \mathrm{C}$ (KLeinert-Giovannini \& IMPERatriz-Fonseca 1986). Assim, M. m. marginata (São Paulo) e $M$. m. obscurior (Rio Grande do Sul) apresentaram comportamento de atividade de vôo semelhante frente às variações de temperatura. Entre as três espécies de Melipona (Illiger, 1806) estudadas (Imperatriz-Fonseca et al. 1985, Kleinert-GiovanNini \& IMPERATRIZ-FonSECA 1986, Hilário et al. 2000) observa-se que as duas subespécies de $M$. marginata exigem maior temperatura para início das atividades de vôo.

A maior intensidade de vôo registrada, na primavera-verão para $M . m$. obscurior, ocorreu na faixa de $81-90 \%$ de umidade relativa (Fig. 5). Estes resultados aproximam-se dos obtidos em São Paulo (90-95\% de umidade relativa) para a mesma subespécie, na mesma estação. Diferentemente, para M. $m$. marginata, a maior intensidade de vôo observada foi sob umidade relativa inferior de 40-70\% (KLEINERT-GIOvanNINI \& IMPERATRIZ-FONSECA 1986).

A radiação solar mínima para as atividades externas de M. $m$. obscurior, na primavera-verão, foi de $2 \mathrm{~W} / \mathrm{m}^{2}$ (Tab. I), tendo ocorrido registro de vôo em todas as faixas subsequentes (Fig. 6). Em São Paulo, estudos com a mesma subespécie, na mesma estação, relatam atividade de vôo relativamente baixa na faixa de 0-10.000 lux (KLEINERT-GiovanNini \& IMPERATRIZ-FonSECA 1986).

Observou-se atividade externa de M. $m$. obscurior em todos os valores registrados para velocidade do vento na primavera-verão (Fig. 7). A redução das atividades de vôo com ventos de 4, 5 e $10 \mathrm{~m} / \mathrm{s}$ deve-se, provavelmente, a alterações de outras variáveis. No outono-inverno, não houve registro de ventos acima de $4 \mathrm{~m} / \mathrm{s}$ e até este valor observou-se atividades de vôo (Fig. 8). Kleinert-GiovanNini \& IMPERATriz-Fonseca (1986) relataram que ventos de $3 \mathrm{~m} / \mathrm{s}$ reduzem as atividades externas em M. m. obscurior e M. m. marginata em São Paulo.

A regressão sazonal dos quatro fatores meteorológicos (temperatura, radiação solar, umidade relativa e vento) com as atividades de vôo das abelhas da colônia A, na primavera-verão, indica influência significativa da temperatura $(r=0,2666$; $p=0,043 ; n=83)$. No outono-inverno a influência da temperatura $(\mathrm{r}=0,365 ; \mathrm{p}=0,020 ; \mathrm{n}=72)$ e da radiação solar $(\mathrm{r}=$ 0,$656 ; \mathrm{p}=0,002 ; \mathrm{n}=52$ ) foram significativas. Em ambos períodos a influência da umidade e do vento não foi significativa nas atividades de vôo.

Nas atividades de vôo das abelhas da colônia B, na primavera-verão, verificou-se influência significativa apenas da radia-

Tabela I. Valores mínimos e máximos dos fatores meteorológicos registrados durante as observações de atividades de vôo e de coleta de pólen de M. marginata obscurior, na primavera-verão (2002/2003) e no outono-inverno (2003).

\begin{tabular}{|c|c|c|c|c|c|c|c|c|}
\hline \multirow[b]{2}{*}{ Período } & \multicolumn{4}{|c|}{ Atividades de vôo } & \multicolumn{4}{|c|}{ Coleta de pólen } \\
\hline & $\begin{array}{c}\text { Temperatura } \\
\left({ }^{\circ} \mathrm{C}\right)\end{array}$ & $\begin{array}{l}\text { Irradiação solar } \\
\left(\mathrm{W} / \mathrm{m}^{2}\right)\end{array}$ & $\begin{array}{c}\text { Umidade } \\
(\%)\end{array}$ & $\begin{array}{l}\text { Vento } \\
(\mathrm{m} / \mathrm{s})\end{array}$ & $\begin{array}{c}\text { Temperatura } \\
\left({ }^{\circ} \mathrm{C}\right)\end{array}$ & $\begin{array}{l}\text { Irradiação solar } \\
\left(\mathrm{W} / \mathrm{m}^{2}\right)\end{array}$ & $\begin{array}{c}\text { Umidade } \\
(\%)\end{array}$ & $\begin{array}{l}\text { Vento } \\
(\mathrm{m} / \mathrm{s})\end{array}$ \\
\hline Primavera-verão & $14,3-26$ & $2-1015$ & $55-100$ & $0-10,3$ & $14,3-25$ & $58-1015$ & $55-100$ & $0-9,8$ \\
\hline Outono-inverno & $13,7-30,5$ & $303-311$ & - & $0-4$ & $15,8-30,5$ & $303-311$ & - & $0-3,6$ \\
\hline
\end{tabular}

Revista Brasileira de Zoologia 22 (3): 680-686, setembro 2005 

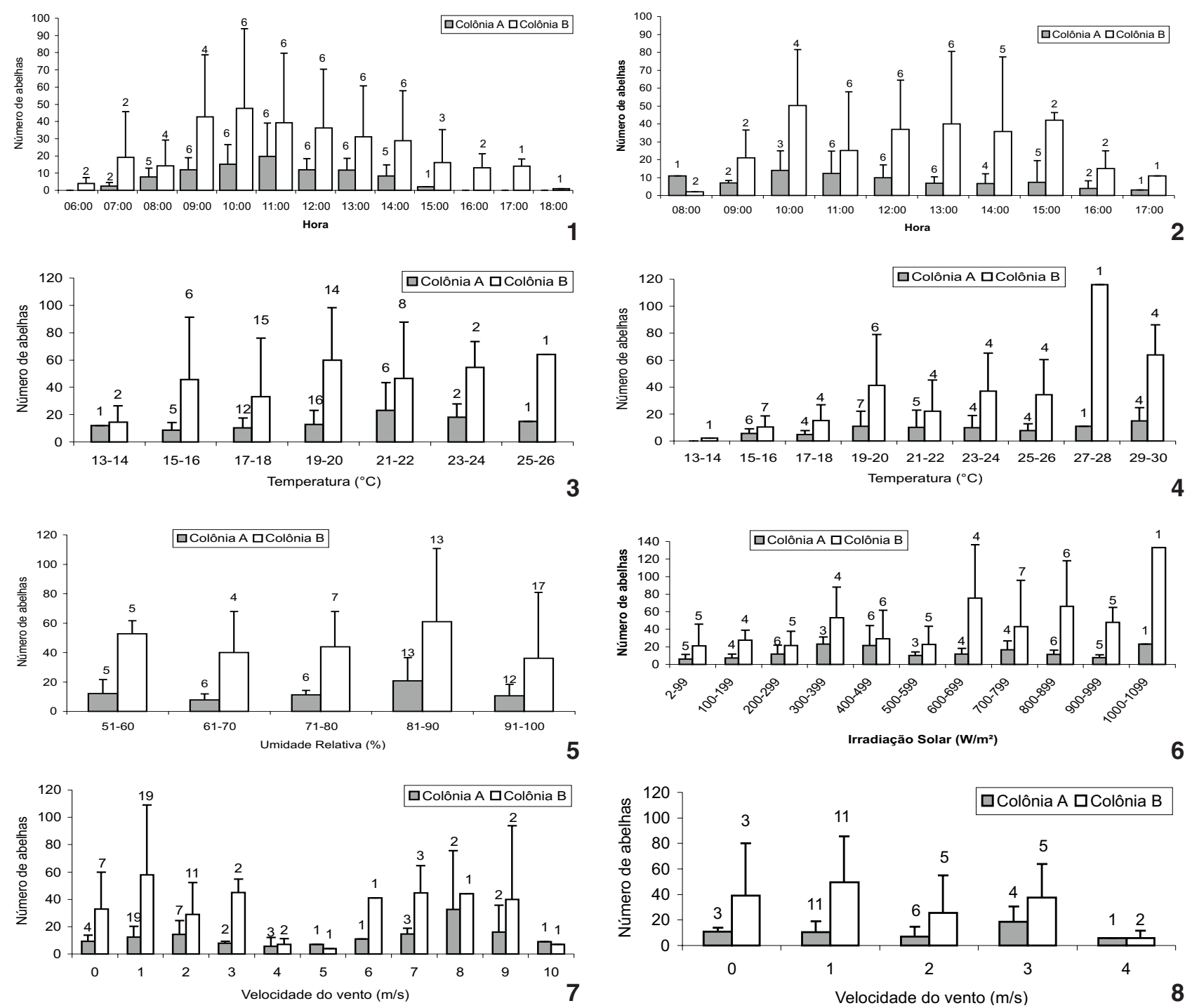

Figuras 1-8. Média e desvio padrão do número de abelhas de duas colônias de M. marginata obscurior que realizavam atividades de vôo durante 10 minutos/hora. (1-2) ao longo do dia: (1) na primavera-verão (2002/2003), (2) no outono-inverno (2003); (3-4) em relação à temperatura: (3) na primavera-verão (2002/2003), (4) no outono-inverno (2003); (5) em relação à umidade relativa, na primaveraverão (2002/2003); (6) em relação à irradiação solar, na primavera-verão (2002/2003); (7-8) em relação à velocidade do vento: (7) na primavera-verão (2002/2003), (8) no outono-inverno (2003). Os números acima das colunas indicam o total de observações.

ção solar ( $\mathrm{r}=0,371 ; \mathrm{p}=0,006, \mathrm{n}=83)$. No outono-inverno, a influência da radiação solar $(r=0,688 ; \mathrm{p}=0,001 ; \mathrm{n}=52)$ e da temperatura $\left(\mathrm{r}=0,603 ; \mathrm{p}=4,7 \times 10^{-5} ; \mathrm{n}=83\right)$ foram significativas. Em ambos períodos o vento não influenciou na atividade de vôo das abelhas. De fato, HeArd \& Hendrikz (1993) e Hilário et al. (2000) destacaram que a temperatura e a radiação solar são fatores importantes na determinação das atividades externas de Trigona carbonaria Smith, 1854 e Melipona bicolor. Além destes dois fatores, a umidade relativa também exerceu influência sobre as atividades de vôo de Plebeia saiqui (Pick \& BLochteIn 2002b).
As atividades diárias de coleta de pólen, na primavera-verão para M. m. obscurior, iniciaram às 7:00 h, havendo um decréscimo nas horas seguintes, cessando às 14:00 h (Fig. 9). Assim, a amplitude máxima diária de coleta de pólen foi de oito horas.

No outono-inverno, as atividades de coleta de pólen iniciaram às 8:00 h, com maior intensidade no final da manhã estendendo-se até às 17:00 h (Fig. 10). A amplitude máxima diária de coleta de pólen foi de 10 horas correspondendo ao intervalo de tempo das atividades de coleta de néctar.

BRUIJN \& SOMMEJjER (1997) assinalaram uma divisão tempo- 

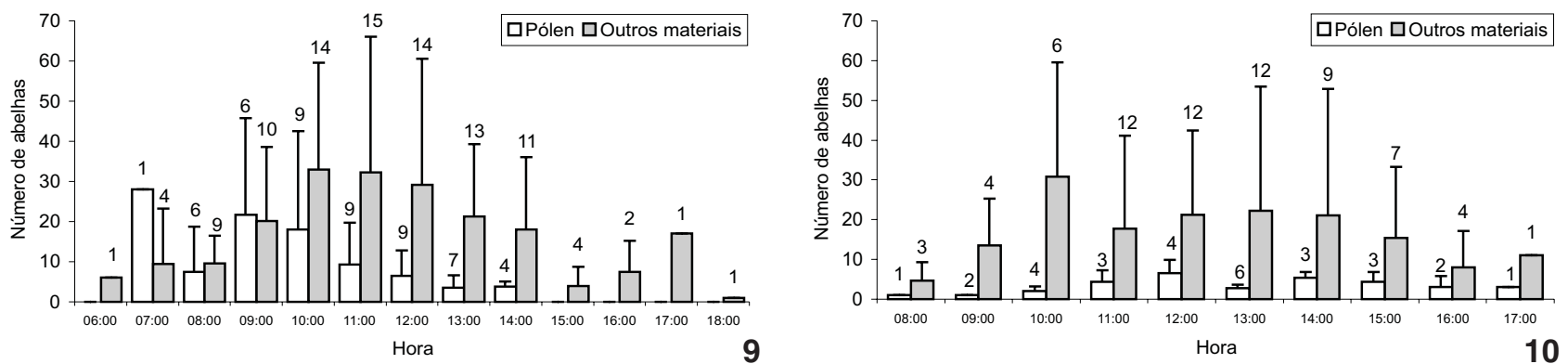

Figuras 9-10. Média e desvio padrão do forrageamento relativo de pólen e outros materiais realizados por operárias de duas colônias de Melipona marginata obscurior (A, B) durante 10 minutos/hora ao longo do dia: (9) na primavera-verão (2002/2003); (10) no outonoinverno (2003). Os números acima das colunas indicam o total de observações.

ral para coletas de néctar, pólen e resina em M. beecheii Bennet, 1831 e $M$. fasciata Latreille, 1811, sendo os seus picos bem separados no tempo. As forrageiras de $M$. marginata obscurior comportaram-se de maneira semelhante, durante a primavera-verão. O maior esforço de coleta de pólen ocorreu nas primeiras horas da manhã (7:00 h) e declinou gradativamente até às 14:00 h, e a maior intensidade de coleta de néctar foi entre 10:00 e 12:00 h prolongando-se até às 18:00 h.

Rouвiк (1989) relaciona um pico matutino de coleta de pólen à disponibilidade deste recurso. Na primavera-verão, o esforço relativo de coleta de pólen de M. marginata obscurior foi maior nas primeiras horas da manhã, quando este recurso é abundante e diminuiu à tarde, provavelmente em decorrência da redução da oferta de pólen devido ao forrageamento de outras abelhas e por outros visitantes florais. Pierrot \& SCHLINDWEIN (2003) estudando M. scutellaris Latreille, 1811, em Pernambuco, também verificaram que o forrageamento de pólen foi mais intenso no período matinal.

O padrão distinto, tardio, de forrageamento de $M$. marginata obscurior, o outono-inverno pode ser relacionado às condições meteorológicas, especificamente temperatura e radiação solar e a menor disponibilidade de recursos florais. A escassez de fontes de pólen neste período deve prolongar o esforço de coleta das operárias de M. marginata obscurior por várias horas do dia. Pierrot \& Schlindwein (2003) atribuíram brusca alteração nos padrões temporais de coleta de pólen de $M$. scutelaris à floração em massa de uma espécie vegetal.

O limite de temperatura registrado para início da coleta de pólen, na primavera-verão, foi de $14,3^{\circ} \mathrm{C}$ (Tab. I), e entre $16-$ $21^{\circ} \mathrm{C}$ as atividades foram mais intensas. Durante o outono-inverno a temperatura para o início das atividades de coleta de pólen foi de $15,8^{\circ} \mathrm{C}$ (Tab. I), com leve aumento das atividades entre $20-31^{\circ} \mathrm{C}$.

Coletas de pólen foram documentadas em todos os intervalos de radiação solar registrados na primavera-verão ( $\mathrm{n}$ = $53)$, enquanto no outono-inverno $(n=32)$ foram verificadas apenas no intervalo de 300-399 $\mathrm{W} / \mathrm{m}^{2}$.

A análise de regressão sazonal dos quatro fatores meteorológicos (temperatura, radiação solar, umidade relativa e vento) indica que não houve influência significativa nas atividades de coleta de pólen da colônia A, durante a primavera-verão. Enquanto que a temperatura $\left(\mathrm{r}=0,531 ; \mathrm{p}=4,14 \times 10^{-4} ; \mathrm{n}=20\right)$ influenciou as coletas de pólen no outono-inverno.

Na colônia B, durante a primavera-verão, a análise de regressão sazonal dos quatro fatores meteorológicos com as atividades de coleta de pólen, indica que radiação solar $(\mathrm{r}=0,281 ; \mathrm{p}$ $=0,037 ; \mathrm{n}=33$ ) influenciou significativamente nas coletas. No outono-inverno a radiação solar $(\mathrm{r}=0,565 ; \mathrm{p}=0,012 ; \mathrm{n}=16)$ e a temperatura $\left(\mathrm{r}=0,607 ; \mathrm{p}=3,27 \times 10^{-5} ; \mathrm{n}=20\right)$ influenciaram significativamente as atividades de coleta de pólen pelas abelhas.

O padrão das atividades externas das operárias de $M$. marginata obscurior diferiu nas distintas épocas do ano consideradas (primavera-verão e outono-inverno) especialmente quanto ao horário de maior intensidade de vôo e de coleta de pólen.

\section{REFERÊNCIAS BIBLIOGRÁFICAS}

ABsy, M.L. \& W.E. KerR.1977.Algumas plantas visitadas para obtenção de pólen por operárias de Melipona seminigra merrillae em Manaus. Acta Amazonica 7 (3): 309-315.

AIDAR, D.S. 1996. A mandaçaia: biologia de abelhas, manejo e multiplicação artificial de colônias de Melipona quadrifasciata Lep. (Hymenoptera, Apidae, Meliponinae). Ribeirão Preto, Sociedade Brasileira de Genética, 104p.

Aidar, D.S. \& L.A.O. Campos. 1998. A influência de fatores climáticos na atividade externa de Tetragonisca angustula (Apidae, Meliponinae). Anais da Sociedade de Entomologia do Brasil 27 (1): 157-159.

Alves-Dos-Santos, I. 1999. Abelhas e plantas melíferas da mata atlântica, restinga e dunas do litoral norte do estado do Rio Grande do Sul, Brasil. Revista Brasileira de Entomologia, São Paulo, 43 (3/4): 191-223.

Bertoletti, J.J. \& M.B. Teixeira. 1995. Centro de Pesquisas e Conservação da Natureza Pró-Mata. Termo de Referência. Divulgações do Museu de Ciência e Tecnologia -UBEA/ PUCRS, Porto Alegre, 2: 1-47.

Bruijn, L.L.M. DE \& M.J. Sommejer. 1997. Colony foraging in different species of stingless bees (Apidae, Meliponinae) and 
the regulation of individual nectar foraging. Insectes sociaux, Paris, 44: 35-47.

Freitas, S.W. \& D. Wittmann. 1997. Poliginia temporária em Plebeia wittmanni Moure \& Camargo, 1989 (Hymenoptera: Apidae, Meliponinae). Biociências, Porto Alegre, 5 (2): 61-69.

Giannini, K.M.; L.R. Bego \& M.D. Marques. 1996. A influência da iluminação direta sobre o processo de aprovisionamento e oviposição de Scaptotrigona depilis (Hymenoptera: Meliponinae). Anais do II Encontro sobre Abelhas, Ribeirão Preto, 2, p. 265.

Guibu, L.S.; M. Ramalho; A. Kleinert-Giovannini \& V.L. ImperatrizFONSECA. 1988. Exploração dos recursos florais por colônias de Melipona quadrifasciata (Apidae, Meliponinae). Revista Brasileira de Biologia, Rio de Janeiro, 48 (2): 299-305.

Heard, T.A. \& J.K. Hendrikz. 1993. Factors influencing flight activity of colonies of the stingless bee Trigona carbonaria (Hymenoptera: Apidae). Australian Journal of Zoology, Queensland, 41: 343-353.

Hilário, S.D.; V.L. Imperatriz-Fonseca \& A. Kleinert-Giovannini. 2000. Flight activity and colony strenght in the stingless bee Melipona bicolor bicolor (Apidae, Meliponinae). Revista Brasileira de Biologia, Rio de Janeiro, 60 (2): 299-306.

Hilário, S.D.; V.L. Imperatriz-Fonseca \& A. Kleinert-Giovannini. 2001. Responses to climatic factors by foragers of Plebeia pugnax Moure (in litt) (Apidae, Meliponinae). Revista Brasileira de Biologia, Rio de Janeiro, 61 (2): 191-196.

Imperatriz-Fonseca, V.L.; A. Kleinert-Giovannini \& J.T. Pires. 1985. Climate variation influence on the flight activity of Plebeia remota Homberg (Hymenoptera, Apidae, Meliponinae). Revista Brasileira de Entomologia, Curitiba, 29 (3/4): 427 434.

IWAMA, S. 1977. A influência de fatores climáticos na atividade externa de Tetragonisca angustula (Apidae, Meliponinae). Boletim do Museu de Zoologia da Universidade de São Paulo, São Paulo, 2: 189-201.

Kerr, W.E.; G.A. Carvalho \& V.A. Nascimento. 1996. Abelha uruçu - biologia, manejo e conservação. Belo Horizonte, Acangaú, $143 p$.

KleinerT-Giovannini, A. 1982. The influence of climate factors on flight activity of Plebeia emerina Friese (Hymenoptera, Apidae, Meliponinae) in winter. Revista Brasileira de Entomologia, Curitiba, 26 (1): 1-13.

Kleinert-Giovannini, A. \& V.L. Imperatriz-Fonseca. 1986. Flight activity and responses to climatic conditions of two subspecies of Melipona marginata Lepeletier (Apidae, Meliponinae). Journal of apicultural research, Cardiff, 25 (1): 3-8.

Kleinert-Giovannini, A. \& V.L. Imperatriz-Fonseca. 1987. Aspects of the trophic niche of Melipona marginata marginata Lepeletier (Apidae, Meliponinae). Apidologie, Les Ulis Cedex, 18 (1): 69-100.

Marques, A. A. B.; C.S. Fontana; E. Vélez; G.A. Bencke; M. Schneider \& R.E. Dos ReIs. 2002. Lista das espécies da fauna ameaçadas de extinção no Rio Grande do Sul. Decreto $n^{\circ} 41.672$, de
11 de Junho de 2002. Porto Alegre, FZB/MCT-PUCRS/ PANGEA, 52p.

Marques, A. A. B.; C.S. Fontana; E. Vélez; G.A. Bencke; M. Schneider \& R.E. Dos ReIs. 2004. Livro Vermelho da fauna ameaçada de extinção no Rio Grande do Sul. Porto Alegre, FZB/MCTPUCRS/PANGEA, 632p.

Michener, C.D. 2000. The bees of the world. Baltimore, The Johns Hopkins University Press, 913p.

Nogueira-Neto, P. 1970. A criação de abelhas indígenas sem ferrão. São Paulo, Chácaras e Quintais, $2^{\mathrm{a}}$ ed., 365p.

Oliveira, M.A.C. 1973. Um método para avaliação das atividades de vôo em Plebeia saiqui (Friese) (Hymenoptera, Meliponinae). Boletim de Zoologia e Biologia, São Paulo, 30: 625-631.

Pick, R. \& B. Blochtein. 2002a. Atividade de coleta e origem floral do pólen armazenado em colônias de Plebeia saiqui (Holmberg) (Hymenoptera, Apidae, Meliponinae) no sul do Brasil. Revista Brasileira de Zoologia, Curitiba, 19 (1): 289 300.

Pick, R. \& B. Blochtein. 2002b. Atividades de vôo de Plebeia saiqui (Holmberg) (Hymenoptera, Apidae, Meliponini) durante o período de postura da rainha e em diapausa. Revista Brasileira de Zoologia, Curitiba, 19 (3): 827-839.

Pierrot, L.M. \& C. Schlindwein. 2003. Variation in dialy flight activity and foraging patterns in colonies of uruçu - Melipona scutellaris Latreille (Apidae, Meliponini). Revista Brasileira de Zoologia, Curitiba, 20 (4): 565-571.

Pirani, J.R. \& M. Cortopassi-Laurino. 1994. Flores e abelhas em São Paulo. São Paulo, Editora da Universidade de São Paulo, FAPESP, $2^{\text {a }}$ ed., 193p.

Ramalho, M.; A. Kleinert-Giovannini \& V.L. Imperatriz-Fonseca. 1989. Utilization of floral resources by species of Melipona (Apidae, Meliponinae): floral preferences. Apidologie, Les Ulis Cedex, 20: 185-195.

Ramalho, M.; V.L. Imperatriz-Fonseca \& A. Kleinert-Giovannini. 1991. Ecologia nutricional de abelhas sociais, p. 225-252. In: A.R. PANIZZI \& J.R.P. PARRA (Eds). Ecologia nutricional de insetos e suas implicações no manejo de pragas. São Paulo, CNPQ, 359p.

RoubIK, D.W. 1989. Ecology and natural history of tropical bees. New York, Cambridge University Press, 514p.

SzABO, T.I. 1980. Effect of weather factors on honeybee flight activity and colony weight gain. Journal of Apicultural Research, Cardiff, 19 (3): 164- 171.

Silveira, F.A.; G.A.R. Melo \& E.A.B. Almeida. 2002. Abelhas brasileiras: sistemática e identificação. Belo Horizonte, IDMAR, 253p.

Wilms, W; L. LutZ; A. Zillikens; B. Blochtein \& W. Engles. 1997. Bees and other insects recorded on flowering trees in a subtropical Araucaria Florest in southern Brazil. Studies on Neotropical Fauna and Environment, Lisse, 32: 220-226. WitTmanN, D. 1989. Nest architecture, nest site preferences and distribution of Plebeia wittmanni Moure \& Camargo in Rio 
Grande do Sul, Brazil (Apidae: Meliponinae). Studies on Neotropical Fauna and Environment, Lisse, 24, (1): 17-23. Wittmann, D. \& M. Hoffmann. 1990. Bees of Rio Grande do Sul, southern Brazil (Insecta, Hymenoptera, Apoidea). Iheringia, Série Zoologia, Porto Alegre, 70: 17-43.

Recebido em 25.X.2004; aceito em 15.VIII.2005.
Wittmann, D.; L.R. Bego; R. Zucchi \& S. Sakagami. 1991. Oviposition beharvior and related aspects of stingless bees XIV. Plebeia (Mourella) caerulea, with comparative notes on the evolution of oviposition patters (Apidae, Meliponianae). Japanese Journal of Entomology, Sapporo, 59 (4): 793-809. 